This is an electronic reprint of the original article. This reprint may differ from the original in pagination and typographic detail.

Please cite the original version: A. Eskelinen, R. Kanervo (2018) Arts-based methods as pedagogical tools in the HEISE project, ICERI2018 Proceedings, pp. 7349-7355.

doi: $\underline{10.21125 / \text { iceri.2018.0306 }}$ 


\title{
ARTS-BASED METHODS AS PEDAGOGICAL TOOLS IN THE HEISE PROJECT
}

\author{
Anne Eskelinen, Riikka Kanervo \\ Laurea University of Applied Sciences (FINLAND)
}

\begin{abstract}
In this article, we describe how arts-based methods are used in different stages of the teaching and learning processes in the courses Methodological Competence in Social Care Sector and Creativity and Activity-Based Methods in Client Work for the first year Social Services Bachelor students in Laurea University of Applied Sciences.
\end{abstract}

This article is part of Erasmus+ Strategic Partnerships funded project called Higher Education Institutions for Societal Engagement (HEISE) which aims at creating an innovative and attractive educational model based on experiential and challenge led learning to increase the higher education institutions' societal engagement. Arts-based methods were used in the courses to understand different points of view when students and work life partners solved different societal challenges together. During the courses, arts-based methods were taught and used as pedagogical tools in teaching and learning.

The material for this article was collected during the academic years 2016-17 and 2017-18 with four different student groups $(\mathrm{N}=118)$ and three senior lecturers. The material consists of the students' reflections and self-evaluations written at the end of the courses as well as the senior lecturers' course materials and common reflections during and after each course.

This article describes and analyzes the students' and teachers' experiences on how arts-based methods can be used and applied in teaching and learning processes. Arts-based methods used in different stages of the course give teachers a deeper understanding of the students' capabilities and space for communication and common understanding. Students gain tools to adapt new skills and to reflect their own actions. Using arts-based methods also offers new ways to interpret the surrounding society and the challenges it is currently facing.

Keywords: Arts-based methods, pedagogical methods, pedagogical innovations, creativity.

\section{ARTS-BASED METHODS IN EDUCATION}

Arts are a part of the school curriculums in almost every country. Through art students can view, explore and broaden their thinking alongside with more scientific and academic subjects. There is still a need for research on how arts education can influence the achievement of soft outcomes and life skills. [1], [2]

In arts there is no right or wrong and it offers a chance to create something new. Art provides a path to explore new things, but also familiar things from another perspective. Innovations play an essential role for economic growth and human wellbeing in the future societies. Arts education can give tools, skills and attitudes needed when creating and producing innovations. It offers a chance to learn critical and creative thinking. [1]

Holden (2006) has named three equally important value dimensions of art. Intrinsic value means that art is valuable as art itself. When art is used as a means to achieve other goals, it has instrumental value. Techniques, structures and processes are emphasized in the institutional value of art. [3] Chemi \& Du (2018) state, that arts-based methods used in education are based on participation and in this context art has instrumental value. Art has always intrinsic value for the artist him/herself, but when the art is used in arts-based purposes the intrinsic value is not always existing. [4]

Academicisation followed by educational reforms in Denmark has led to a situation, where it is hard and sometimes even impossible for students of social education to build bridges between theory and complex situations their face during their practical training and when entering work life after graduation. Borup Jensen (2017) indicates that through arts-based teaching students were able to develop a personal relationship to professional concepts and theories. Arts-based pedagogy activate the student's personal experiences and bodily knowledge, and thus enables them to make 
connections between theory and practice. Arts can provide students an opportunity to process theorybased knowledge, experiences and reflections through artistic activities. [5]

According to Taylor \& Ladkin (2009) arts-based methods are underpinned by four distinctive processes in managerial development work: 1 . skills transfer, where art-based methods can facilitate the development of specific (artistic) skills, 2. projective technique, where arts-based method can open the access to inner thoughts and feelings and where the arts can foster reflection by using for example metaforas 3.illustration of essence, where art is an object that can be reflected on, rather than as a way to evoke personal meanings to it and 4.influencing, where creating and making art have the main focus, and the process of creating results in influence of some kind. [6]

Arts-based methods give means to view world from another person's point of view, and thus create understanding and enable us to be emphatic. Arts also teaches us that we all experience and see things differently. Känkänen \& Bardy (2014) argue that arts-based methods can open a free space without the normative sphere. This free space without right or wrong gives us an opportunity to discuss, make questions and continue exploring different phenomenons without limitations or preconceptions. It helps us express ourselves in different ways using different techniques and having control-free zone which can offer new ways for self-expression in a form of metaphoric shelter. [7] Gladding (2016) states that arts-based methods involve energy and process and they enable participation, interaction and co-operation. We can say that arts empower people and on individual level arts can open windows to see the simplicity and complexity of one's life clearly. Art-based methods also offer adults the opportunity to be creative and play. [8]

Cramer et al. (2017) argue, that arts-based projects can benefit social work students' learning more than art creation projects, where students have to create art. Art-based working methods offer learning opportunities through art: painting and taking photos or through making music. They can help students to express themselves or deepen emotional and cognitive understanding of other individuals. Artbased methods can provide new perspectives or they can offer a channel for critical reflection. Visual, verbal, nonverbal and experiential learning are the forms of learning through art-based methods and they give opportunity to multimodal learning. [9]

\section{DEVELOPMENT WORK IN THE HEISE PROJECT}

HEISE project aims at creating an innovative and attractive educational model based on experiential and challenge led learning to increase the higher education institutions' societal engagement. The focus is in projects, where work life partners and students are working in joint teams and solving challenges together with art-based methods in what we call "challenge solving projects".[10] Challenge in this setting is understood in a very broad way: as a problem or a challenge that an organisation, group of people or an individual is tackling with. Challenge solving projects aim to solve these challenges together by using arts-based methods.

Social services students from Laurea University of Applied Sciences have taken part in the HEISE project during the academic years 2016-17 and 2017-18 with four different student groups $(\mathrm{N}=118)$. Arts-based methods have been used in teaching, in learning and in reflection during the study units called "Methodological Competence in Social Care Sector" and "Creativity and Activity-Based Methods in Client Work" for the first year Social Services Bachelor students. Before the courses began we stated that arts-based methods can be used in three different ways: in teaching, in the students' challenge solving projects and in reflection during and at the end of the course. Arts-based methods were used as pedagogical tools during the lectures, but also in the students' challenge solving projects carried out during these courses. Arts-based methods were used to create common understanding amongst students and work life partners when they were solving different societal challenges together. Our view was built on theory mentioned in the previous chapter, but also on our own experiences as senior lecturers.

\subsection{Arts-based methods as pedagogical tools in teaching and learning}

Arts-based methods can be used in various pedagogical ways. During the courses there were drama, dance and movement, visual art and music workshops for students. Main idea behind the workshops was to provide students experiences and examples about different methods and techniques. Workshops aimed also to feed the students' imagination and creativity, so that they would have the skills and courage to use these methods themselves. 
Workshops offered a platform for own experiences and discussions about arts-based methods and communication and to provide examples on how to use arts-based methods in social impact work. Students had to ponder how arts-based methods can be used when aiming for social impact amongst the clients and in the society. Experiential learning offered a joint ground for discussions and also ethical pondering: how and when to use certain methods and also what should be kept in mind when using different methods.

Using creativity and arts-based methods enable students to reflect their own behavior and thinking and deepen their understanding of others and the surrounding world. The students made their learning process visible through different arts-based activities in the different stages of the course. During the courses students reflected their personal process, but also their role as a team member. Art-based methods provide students with a solid foundation on which to build on their competences for the future. Arts-based methods also increase respect towards other people, and their input and capacities.

\subsection{Arts-based methods in challenge solving projects}

In the beginning of the courses students were given instructions about the challenge solving project, that they were about to perform as a part of this study unit/course. Student teams were using artsbased methods such as writing poems and rap lyrics, when brainstorming and throwing ideas about their projects. As the student teams started the co-operation with professional networks and work life partners they began to report their project and its process through social media channels. Instagram and YouTube were used to share their pictures and video clips, and to report their project to the teachers and peer students.

Students planned and carried out challenge solving projects with different work life partners. In these projects students used arts-based methods with different client groups and in different professional settings, such as early childhood education, young people, elderly, children, mentally disabled adults, substance and mental health rehabilitees, immigrants and multicultural families. Work life partners were mostly non-profit organisations and associations, but also public service providers, such as day care centers and elderly homes. Some partnerships were established by the students themselves, and the initiative for the project came from them. Some of the work life partners have been co-operating with Laurea UAS for a longer period of time.

Challenge solving projects tackled with a variety of societal challenges, such as mental health, substance abuse, lowered functional capacity among elderly, disabilities, immigration and also promoting well-being and participation with children and young people. Students were also organizing anti-racism workshops in kindergartens. Student projects utilised different arts-based methods, such as music, visual arts, drama and handicrafts, all of which were chosen according to the challenge owners needs and wishes. Social impact assessment and constant evaluation and reflection during the project were emphasized during the pedagogical process. Students were encouraged to analyze the chosen arts-based methods on individual, community and also on the societal level.

\section{MATERIAL AND ANALYZES}

The material for this article was collected during the academic years 2016-17 and 2017-18 from the courses Methodological Competence in Social Care Sector and Creativity and Activity-Based Methods in Client Work for the first year Social Services Bachelor students. Material consists of students' reports and reflections and teachers' reflections during and after the courses. Material was gathered with four different student groups $(\mathrm{N}=118)$. Ongoing reflection by the teachers made different pedagogical approaches, methods and duration of processes visible. The material was analyzed and categorized in two dimensions we call students' individual and professional dimension.

\section{RESULTS}

\subsection{The Students' Learning Outcomes}

At the end of the course students wrote about their learning outcomes and own performance during the course. Students reflected their personal learning process in creative way. These 'pearls of learning' were presented in the final seminar. Each student team also produced a report, where they described their challenge solving project as a whole: the moments of success and also the obstacles they faced during the projects. These writings and reports were analyzed with content analysis. 
Students' learning outcomes were divided into two dimensions: individual dimension and professional dimension.

\subsubsection{The Students' Individual Dimension}

The students described that one of the biggest learning outcomes was the realization, that creativity does not mean the same thing to everyone. People see and experience things differently. Creativity can take different forms and shapes in different situations.

"There was no right or wrong - an amazing way to practice your creativity".

Some of the students were not very excited when the course started, because they didn't think that they can be creative or expressive. They described that courses gave and taught them a lot, not just about methods, but also about themselves and how they see themselves. Students noticed that it could be easier to express oneself and to show how something is done by physical movement or by drawing something, rather than having to write words on paper.

Arts-based methods workshops offered students different ways to express themselves and they had an opportunity to get experiences from different methods - also those they didn't like. Some students were very critical and for example did not want to show their paintings to anyone or dance with others. Even if the students didn't enjoy all workshops and methods, they realized that it was interesting to go on a personal journey. Students found different skills they are good at and learned more creative ways to work. They liked to try new things but also old things they did not enjoy before. All and all students got aware of their own skills and saw the importance of all the different methods.

"... it was fun to get out of my comfort zone having to do different acts and tasks in front of the class. By doing so it helped me see how others might feel if put in the same position."

Some students felt that arts-based methods brought them closer with the other students in the class. They could see everyone's different point of views and for example how different music really is to everyone. The students appreciated each other's opinions and liked to share experiences.

Like one student said: "...gave us space and freedom from our heads, freeing ourselves of the thought what the process should be like, and how the outcome should look like."

Arts-based methods can unfold a lot of feelings inside of us and students had realized that it was important to mirror and reflect the methods together and individually after the classes. The feelings can explain and clarify to us what we are going through.

"This course has given me space not only to go through hardships, but also to dream and be happy. Let's see where it takes me!"

\subsubsection{The Students' Professional Dimension}

Challenge solving project work taught students to plan, carry out and evaluate a project. Student teams used different arts-based methods when working with clients and work life partners. Applying arts-based methods enhanced students' creativity, stress tolerance, flexibility and problem solving skills. Working as a member of a team taught students tolerating differences and solving disagreements in a professional manner.

"We learned to work together, even though we didn't always think alike, and at the end produced something amazing."

In the challenge solving projects students realized how important it is to meet each client as an individual and without prejudice, so that the person feels equal, appreciated and valued. Some of the clients the students met in the beginning of their projects seemed really fragile, and this made the students feel uncertain and also scared about their own skills and competencies. However trusting the process, being open to the clients' wishes and needs enabled the students face the people genuinely and on their terms. Humor, joy and giving positive feedback to the participants played an essential role during the creative activities.

"It is important to meet with the person, not the diagnosis."

Arts-based methods provided a great way of non-verbal communication, interaction and selfexpression in the students' projects. The students learned a lot about non-verbal communication and how it can be used in different situations. Sometimes using arts-based methods and creativity offer a channel for expressing one's feelings and thoughts and this can be much more effective than having 
to communicate one's issues verbally. The starting point in the challenge solving projects for the students was that they did not try fix anyone's problems nor cure the illnesses, but to face the group members as individuals through arts-based methods. One student group described that the project was a dream of a holistic learning journey, where everyone learned from each other.

"Even though the clients were not able to communicate verbally, the noises they made and their facial expressions showed that they were enjoying themselves."

According to the students creating a positive and safe environment to the group was vital. Routines in the beginning and at the end of each session create safety and predictability to the clients, even if each session was different and contained different elements and different creative activities. Also planning the sessions together with the clients was important, and increased the motivation to participate in the sessions. When leading a group activities it is important to proceed with tiny steps, so that each member of the group can take part according to their own capabilities and resources. First sessions were built on easy activities and on individual participation. As the process went further, sessions offered more challenges and group activities. Projects offered clients a possibility to try out new things and to work as a group.

"Some clients took part in the activities, some were able to start talking about their thoughts and experiences. Everyone took part according to their own abilities."

\subsection{The Teachers' Experiences}

Teachers reflected their own work constantly during and between the courses in joint meetings. This reflection resulted to clarifying instructions and assignments, but also in creating new pedagogical approaches for the learning objectives of the courses. The students' feedback also contributed to the development work of the courses. According to students' feedback integrating two courses into one entity was not clear for all students. There were different kind of instructions for the tasks and project work and the students didn't know which tasks belonged to which course. Also the learning platform of the courses was unclear and the timetable for the courses seemed too hectic for the students. Teachers modified the exercises and assignments and changed the course program according to students' feedback.

The teachers noticed that the students needed more detailed instructions to start their work with working life partners and to create a realistic project plan. Hence the teachers created new detailed instructions for students' challenge solving project work. For example, students needed to describe the aims of their project at the level of the society, the community and individuals. Collecting feedback from the project partners and clients involved in the project in a structured way was emphasized in the new instructions. The teachers decided also to divide students into smaller 2-3 persons groups than in the previous projects in order to give each student more responsibility in projects and to strengthen the students' professional growth.

In the beginning of the courses some students expressed concern about arts-based workshops and creative activities as well as creativity in general. These students didn't think they had any creativity in them. Workshops and lessons contained many discussions about the students' previous experiences of arts-based methods and creativity and the "know-how" of arts-based methods. To ease the process for the students, the course started with easy methods that can be applied to client work easily. The leading idea is that everyone can be creative without special skills and abilities.

The teachers noticed that after attending the workshops and trying different creative methods themselves, students were professionally prepared, ready and eager to use art-based methods in their challenge solving projects. Art-based methods seemed to give the students tools to interact with clients in a deeper and more meaningful way. In the challenge solving projects the emphasis was on sharing feelings and thoughts but also on working together with clients by using arts-based methods.

The teachers were using different arts-based methods to support the students' learning during the course and project work. Selected methods such as making short films, dramas and poems deepened the students' reflections and made the situations visible for other students. They helped to realize problems students were facing in their projects and on the other hand helped students to solve them. Biggest realization for the teachers was that integrating arts-based methods to teaching, learning and challenge solving processes developed students' not only professionally but also personally. Artsbased methods strengthened also group cohesion that was seen in the interaction of the students during lessons and the challenge solving processes. 


\section{CONCLUSIONS}

At the end of the courses students were given a task to reflect their own learning process and most meaningful learning outcomes by using a creative method of their own choice. These "pearls of learning" were shared in the classroom. During the course students made a personal journey to themselves and were faced with also uncomfortable feelings and memories. Sharing parts of this journey in front of a classroom full of fellow students and teachers required courage from the performer, but also emphatic and safe atmosphere. Seeing and hearing other students presenting their experiences through a painting, a poem or a song is a powerful experience. Students learned new things about each other and felt that this experience has brought for them closer. These elements of learning through sharing as a part of students professional growth are recognized also in Cramer et al (2017) and Borup Jensen (2017) researches [5],[9].

The students felt that they managed well in guiding arts-based methods in the challenge solving projects. They developed their professional skills and competences and inspired creativity among the clients through arts-based workshops. The use of arts-based methods in education of social services bachelor students aimed at students acquiring skills for future working life. Arts-based methods can be seen as professional tools used in the client work, tools for professional growth and self-expression. They also provide tools for coping both during and after studies when entering working life. According to future working life reports [11],[12],[13] we need more creativity, fluent communication and interpersonal skills. Ability to adapt and adjust oneself to constant changes, flexibility and tolerating uncertainty are seen as needed skills for an employee. As professional scenes are complex and changes happen in fast cycles, workers are required to have reflection skills and ability create their own professional networks. [11],[12],[13] One of the solutions for the growing demands of the future working life can be considered arts, arts education and arts-based methods [1], [2], [4], [6].

Based on our HEISE project development work we state that arts-based methods increase empowerment, interaction and sense of belonging in the local community and also in the society. HEl's don't operate in a vacuum, but as a part of the surrounding society. Challenge solving projects that utilized arts-based methods enable communication and expressing oneself also for those who have challenges in communication. Arts-based methods enable individual to be seen and heard, whether they are students or clients in a social welfare services. It can be concluded that arts-based methods enable sharing one's feelings and thoughts even if it would be otherwise impossible. Arts provide us a window into other people's experiences. Arts-based methods help us to deepen our understanding of the multifaceted and diverse world we are living in.

\section{REFERENCES}

[1] E. Winner, T. Goldstein and S.Vincent-Lancrin, Art for Art's Sake? Overview, OECD Publishing, 2013. Retrieved from http://www.oecd.org/education/ceri/ART\%20FOR\%20ART'S\%20SAKE\%200VERVIEW_EN_R3 .pdf

[2] Arts Council England, The Value of Arts and Culture to People and Society. An evidence review. Retrieved from http://www.artscouncil.org.uk/sites/default/files/downloadfile/Value_arts_culture_evidence_review.pdf . 2014.

[3] J. Holden, Cultural value and the Crisis of Legitimacy Why culture needs a democratic mandate. London: Demos, 2006.

[4] T. Chemi and X. Du (Eds.) Arts-based Methods and Organizational Learning Higher education around the world, Palgrave Macmillan, 2018.

[5] J. Borup Jensen, "Sensing the Problem Instead of Just Talking about It: Arts-Based Pedagogies and Development of Innovative, Professional Identities in Social Education Studies" In Innovative Pedagogy,(eds. T. Chemi, S. Grams Davy and B, Lund), pp. 45-57, Rotterdam: Sense Publishers, 2017.

[6] S. Taylor and D. Ladkin, "Understanding Arts-based Methods in Managerial Development", Academy of Management Learning and Education 8 (1), pp. 55-69, 2009.

[7] P. Känkänen and M. Bardy. Life stories and arts in child welfare: enriching communication, Nordic Social Work Research, 4:1,pp. 37-51, 2014. Retrieved from http://dx.doi.org/10.1080/2156857X.2013.781536. 2014 
[8] S. T. Gladding. The Creative Arts in Counseling, American Counseling Association, 2015.

[9] P. Cramer, D.A. MCLeod, M. Craft and K. Agnelli, "Using arts-based material to explore the complexities of clinical decision-making in a social work methods course", Social Work Education Vol. 37, No. 3, pp. 342-360, 2017.

[10] HEISE project, Higher education institutions for societal engagement, Accessed 19 September 2018. Retrieved from http://www.mapsi.eu/heise/.

[11] Työelämä 2025 -katsaus, Työelämän ja työympäristön muutosten vaikutukset työsuojeluun ja työhyvinvointiin, Työsuojeluosasto, Sosiaali- ja terveysministeriön raportteja ja muistioita 2015:16, 2015.

[12] T. Alasoini, A. Järvensivu and J. Mäkitalo, Suomen työelämä vuonna 2030, Miten ja miksi se on toisennäköinen kuin tällä hetkellä, Työ- ja elinkeinoministeriö, TEM raportteja, 14/2012, 2012.

[13] L. Penttinen, T. Skaniakos, M. Lairio and J. Ukkonen," Korkeakouluopiskelun pedagoginen työelämähorisontti, Miten työelämäorientaatiota voidaan tukea koulutuksen aikana", Aikuiskasvatus, 2/2011, 2011. 